\title{
Peningkatan Kemampuan Manajemen Wirausaha Untuk Pedagang Kaki LIMA DI LINGKUNGAN KAMPUS UNISBA
}

\author{
ENHANCING THE ENTREPRENEURIAL MANAGEMENT SKILLS FOR STREET VENDORS AT \\ UNISBA CAMPUS ENVIRONMENT \\ ${ }^{1}$ Reni Amaranti, ${ }^{2}$ Nugraha, ${ }^{3}$ Ahmad Arif N., ${ }^{4}$ M. Dzikron \\ ${ }^{1,2,3}$ Fakultas Teknik, Universitas Islam Bandung, Jl. Tamansari No. 1 Bandung 40116 \\ email : ${ }^{1}$ reniamaranti2709@yahoo.com, ${ }_{-}^{2}$ Nugraha692004@yahoo.com; ${ }^{3}$ nurrahman18@yahoo.com; \\ ${ }^{4}$ mdzikron@gmail.com
}

\begin{abstract}
The existences of street vendors who sell their products around campus of Unisba slightly disturb the comfort and cleanliness of the campus environment. Nevertheless, the presence of street vendors has provided an alternative for Unisba students to get food and drink while on campus, although students can also buy food in the campus cafeteria or in the student cooperative. Initial observations show that the way the vendors' trade does not change over time, even though they have been selling for years and even decades. Simple business management has led to significantly stagnant businesses growth. This community service activities aim to increase the entrepreneurship management skills of these street vendors so that they can manage their businesses to grow significantly. Community service is done by providing training and assistance in business management, including production management, simple financial management, and marketing. To reduce the saturation of trainees, training is not done in the classroom. It also initiated the formation of merchant associations to facilitate coordination and communication among traders or between traders and other parties. The results of this activity indicate that there is an increase knowledge of street vendors about how to manage their businesses and most of the trainees are satisfied with the implementation of the training. Street vendors expect similar activities to be conducted on a regular basis with different training materials so that their abilities increase.
\end{abstract}

Keywords: the entrepreneurship management capability, community service, street vendors

\begin{abstract}
Abstrak. Keberadaan para pedagang kaki lima yang berjualan di sekitar kampus unisba saat ini sedikit mengganggu kenyamanan dan kebersihan lingkungan kampus. Walaupun demikian, keberadaan pedagang kaki lima tersebut telah memberikan alternatif bagi mahasiswa Unisba untuk mendapatkan makanan dan minuman selain di kantin kampus atau di koperasi mahasiswa. Pengamatan awal menunjukkan bahwa cara berdagang yang mereka lakukan tidak berubah dari waktu ke waktu, padahal mereka sudah berjualan bertahun-tahun bahkan puluhan tahun. Manajemen usaha yang sangat sederhana menyebabkan usaha tidak berkembang secara signifikan. Kegiatan pengabdian pada masyarakat ini bertujuan untuk meningkatan kemampuan manajemen wirausaha dari para pedagang kaki lima tersebut sehingga mereka dapat mengelola usahanya dengan lebih baik dan usahanya dapat berkembang secara signifikan.Pengabdian pada masyarakat ini dilakukan dengan memberikan pelatihan dan pendampingan mengenai manajemen usaha, meliputi manajemen produksi, manajemen keuangan sederhana, manajemen produksi, dan pemasaran. Untuk mengurangi kejenuhan peserta pelatihan, pelatihan tidak dilakukan dalam kelas. Selain itu juga dilakukan inisiasi pembentukan paguyuban pedagang untuk memudahkan koordinasi dan komunikasi antar pedagang atau antara pedagang dengan pihak lain. Hasil kegiatan ini menunjukkan bahwa terjadi peningkatan pada pemahaman para pedagang mengenai cara mengelola usaha mereka dan sebagian besar peserta pelatihan merasa puas dengan pelaksanaan pelatihan yang dilakukan. Para pedagang mengharapkan kegiatan serupa dilakukan secara rutin dengan materi pelatihan yang berbeda sehingga kemampuan mereka semakin bertambah.
\end{abstract}

Kata Kunci: kemampuan manajemen wirausaha, pedagang kaki lima 


\section{Pendahuluan}

Pedagang Kaki Lima (PKL) adalah salah satu profesi yang terjadi akibat semakin sempitnya lapangan pekerjaan di sektor formal sehingga sebagian masyarakat beralih ke sektor informal demi kelangsungan hidupnya. Karakteristik PKL yang menggunakan ruang untuk kepentingan umum, terutama di pinggir jalan dan trotoar untuk melakukan aktivitasnya yang mengakibatkan tidak berfungsinya sarana-sarana kepentingan umum. Tidak tertampungnya kegiatan PKL di sarana yang disediakan di perkotaan, menyebabkan pola dan struktur kota moderen dan tradisional berbaur menjadi satu sehingga menimbulkan suatu tampilan yang kontras. Bangunan moderen nan megah berdampingan dengan bangunan sederhana bahkan cenderung kumuh.

Kehadiran PKL tidak sedikit menimbulkan berbagai permasalahan di lingkungan sosial, seperti lingkungan kumuh, kesehatan yang tidak terjamin dari produk yang dihasilkan, dan kemacetan karena beraktivitas di bahu jalan. Begitupula kehadiran PKL di Unisba. Kondisi Unisba dengan bangunan yang modern dan megah berdampingan dengan PKL menimbulkan berbagai persoalan. Keberadaan kios-kios PKL yang saat ini ada di depan kampus Unisba menimbulkan kesan yang kurang baik terhadap tampilan kampus Unisba karena cara penanganan dan pengaturannya yang cenderung asalasalan, sangat kontras dengan penampilan Kampus Unisba yang moderen dan megah. Permasalahan lain yang muncul berkaitan dengan keberadaan pedagang kaki lima di depan kampus Unisba adalah masalah kebersihan. Perilaku para pedagang yang kurang "aware" terhadap kebersihan tempat mereka berjualan menyebabkan lingkungan depan Kampus Unisba cenderung kumuh dan kotor. Maka dari itu kami merasa perlu untuk melakukan bimbingan kepada PKL Unisba agar mereka mampu mengelola usahanya secara baik. Bimbingan tersebut dapat berupa pelatihan manajemen kewirausahaan agar mereka dapat mengelola usahanya secara lebih propesional, hygenis, dan aman bagi para konsumennya.

Tujuan secara kegiatan Pengabdian Kepada Masyarakat-Program Pembinaan Usaha Mikro, Kecil, dan Menengah (P2UMKM) adalah meningkatnya kemampuan manajemen wirausaha untuk pedagang kaki lima di lingkunan Unisba, sedangkan secara khusus bertujuan untuk: 1) Terlaksananya pelatihan manajemen wirausaha untuk pedagang kaki lima di lingkungan Unisba, 2) Meningkatkan keterampilan pedagang kaki lima di lingkungan Unisba seperti pemberian materi pengetahuan dasar kewirausahaan, manajemen produksi, manajemen keuangan, dan manajemen pemasaran Selain itu, diakhir pelatihan, para peserta diharapkan berkenan untuk membuat sebuah paguyuban pedagang kaki lima untuk senantiasa memantau perkembangan dari setiap anggota pedagang kaki lima Unisba..

\section{Tahap Pelaksanaan}

Inti kegiatan pengabdian masyarakat yang dilakukan adalah palatihan dan pendampingan. Kegiatan dibagi menjadi beberapa tahap yaitu, tahap persiapan, tahap sosialisasi, pelaksanaan pelatihan dan pendampingan, tahap monitoring dan evaluasi. Tahap persiapan meliputi kegiatan observasi awal untuk menentukan inti permasalahan yang akan ditangani berkaitan dengan pedagang kaki lima di lingkungan kampus Unisba, merumuskan metode dan solusi yang akan diberikan dan membuat rencana pelaksanaan kegiatan.

Tahap sosialisasi dilakukan dengan menginformasikan kegiatan kepada pedagang kaki lima dengan cara berdialog dengan para pedagang dan membuat poster. Sosialisasi dilakukan oleh mahasiswa anggota tim sehingga prosesnya tidak dilakukan 
secara formal. Langkah selanjutnya adalah membuat rencana pelatihan, pendaftaran peserta pelatihan, mempersiapkan materi pelatihan serta narasumber. Pada kegiatan pelatihan, peserta dibatasi hanya untuk 20 orang pedagang. Pedagang lain yang tahun ini belum bisa ikut serta dalam pelatihan akan diutamakan untuk mengikuti kegiatan lain di waktu yang akan datang. Walaupun demikian, kegiatan lain selain pelatihan dapat diikuti oleh semua pedagang. Monitoring dan evaluasi pelaksanaan kegiatan dilakukan untuk mengetahui kelebihan dan kekurangan dari pelaksanaan kegitan terutama kegiatan pelatihan. Hasil evaluasi menjadi dasar perbaikan pelaksanaan kegiatan sejenis di waktu yang akan datang. Semua tahapan dan hasil pelaksanaan kegiatan pengabdian pada masyarakat ini kemudian dipaparkan dalam laporan pelaksanaan kegiatan dan juga disampaikan dalam seminar. Tahapan pelaksanaan pengabdian masyarakat ini secara lengkap digambarkan pada Gambar 1.

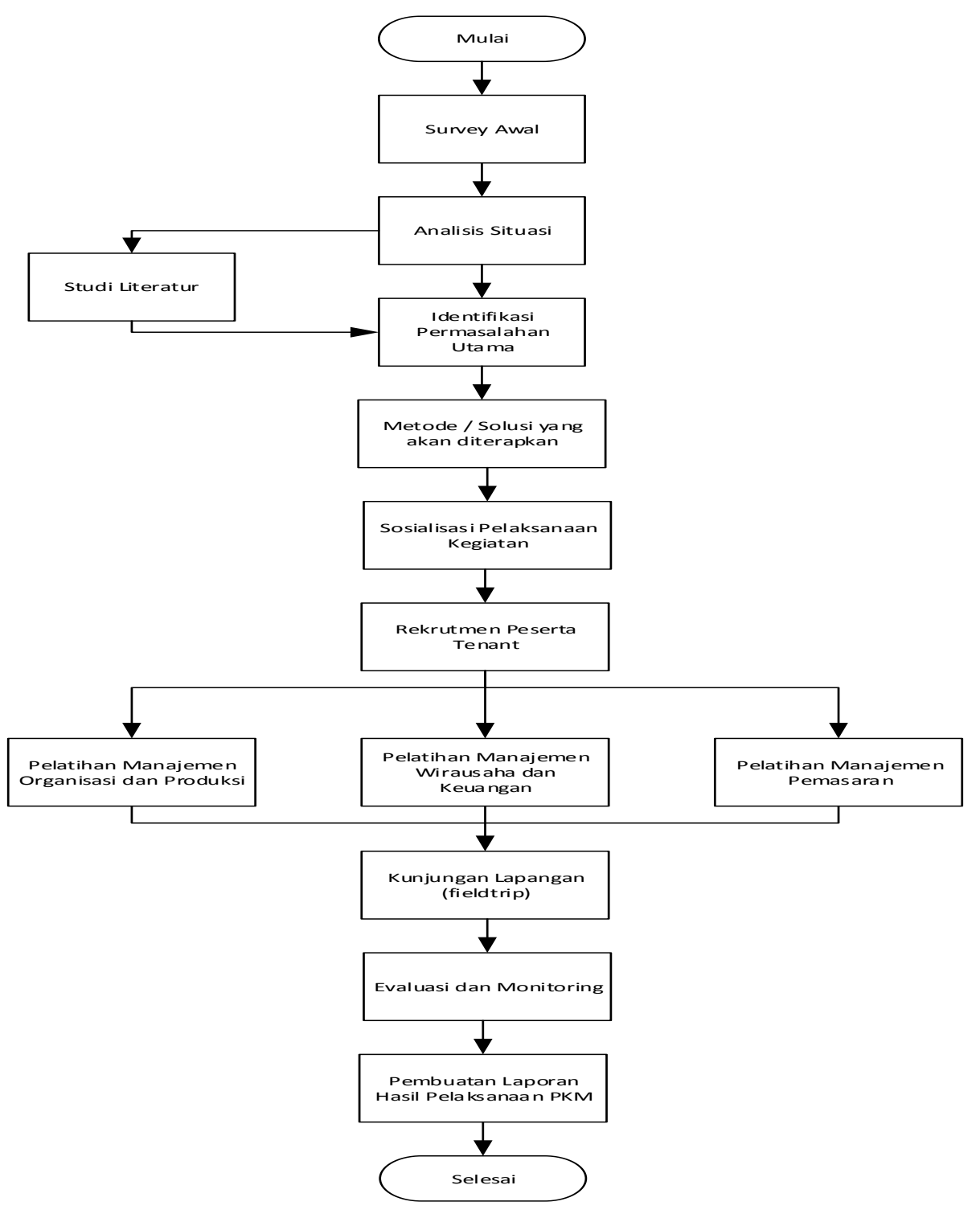

Gambar 1. Tahapan Pelaksanaan PKM-P2UMKM. 


\section{Hasil dan Pembahasan}

Tahap persiapan diawali dengan pembahasan mengenai rencana kegiatan pelatihan manajemen wirausaha untuk pedagang kaki lima yaitu membuat jadwal pelatihan, penentuan jumlan peserta pelatihan, penyusunan konsep pelatihan, rencana sosialisasi, pembuatan modul pelatihan, dan nara sumber.

Tahap sosialisasi dimaksudkan untuk menginformasikan tema kegiatan pelatihan, tujuan pelatihan, jenis pelatihan, jadwal kegiatan pelatihan, dan ketentuan peserta pelatihan.Sosialisasikegiatan pelatihan dilakukan dengan dua cara, yaitu melalui poster terbatas dan melalui mulut ke mulut (Word of Mouth). Mengingat pesertanya terbatas, maka poster yang dibagikan pun sangat terbatas, poster yang dibagikan hanya lima buah yang kemudian secara mulut ke mulut pedagang kaki lima diminta mengajak 3 sampai 5 orang temannya untuk menjadi peserta pelatihan. Cara ini dinilai efektif karena gabungan antara poster terbatas dan penyebaran informasi dari mulut ke mulut ini membuat seleksi terhadap calon peserta pelatihan lebih mudah dan lebih cepat.

Tahap selanjutnya adalah rekrutmen peserta pelatihan dimulai dengan pengisian biodata/surat kesediaan menjadi peserta pelatihanoleh para pedagang bersedia mengikuti pelatihan sampai selesai. Peserta pelatihan dibatasi hanya 22 orang tanpa memperhatikan produk yang dijual.

Kegiatan pelatihan dilaksanakan di luar kampus Unisba. Beberapa hal yang menjadi pertimbangan dalam menentukan konsep dan materi pelatihan adalah :

1. Materi Pelatihan yang diberikan selain membahas mengenai manajemen usaha juga ditambah dengan sharing dari pedagang kaki lima yang telah berhasil mengembangkan usahanya. Materi pelatihan diperlukan untuk membantu dan membekali pengetahuan pedagang kaki lima (PKL) agar dapat mengelola bisnisnya menjadi lebih profesional dengan sistem manajemen yang baik.

2. Peserta pelatihan adalah para pedagang yang tingkat pendidikannya sebagian besar tidak tinggi, oleh karena itu penyampaian materi dirancang tidak formal dan tidak dilakukan dalam ruang kelas.

Pelatihan dilaksanakan satu hari dengan materi terdiri dari: Tips mengenali tipe pelanggan; Layanan Pelanggan (Customer Service); Menarik konsumen dengan kemasan menarik; Tips manajemen keuangan; Kiat pengembangan usaha; Maju bersama Koperasi, dan Inspirasi PKL sukses. Pelatihan diselenggarakan di tempat wisata Situ Patenggang, Ciwidey, Kabupaten Bandung dengan maksud agar pedagang kaki lima (PKL) lebih antusias mengikuti pelatihan, jika dibandingkan dengan pelatihan-pelatihan kewirausahaan lain yang biasa diselenggarakan lembaga lain. Agar pelatihan lebih berkesan, peserta pelatihan pun dibawa kunjungan ke Cafe Madtari sebagai salah satu inspirasi PKL yang telah sukses mengembangkan usahanya. Kunjungan ini dimaksudkan memberi motivasi kepada para PKL agar mereka senantiasa bersemangat menjalankan usahanya dan berusaha memperbaiki manajemen usaha nya agar menjadi lebih baik di waktu yang akan datang.

Setelah pelatihan, dilakukan evaluasi untuk melihat respon peserta pelatihan terhadap kegiatan pelatihan yang diselenggarakan. Evaluasi ini dilakukan melalui pengisian kuesioner sederhana yang memaparkan tentang pelaksanaan kegiatan dari awal sampai akhir. Hasil evaluasi ini akan digunakan untuk perbaikan penyelenggaraan kegiatan yang sama di masa yang akan datang, sehinga pelatihan yang melibatkan pedagang kaki lima dapat diselenggarakan secara lebih baik. 


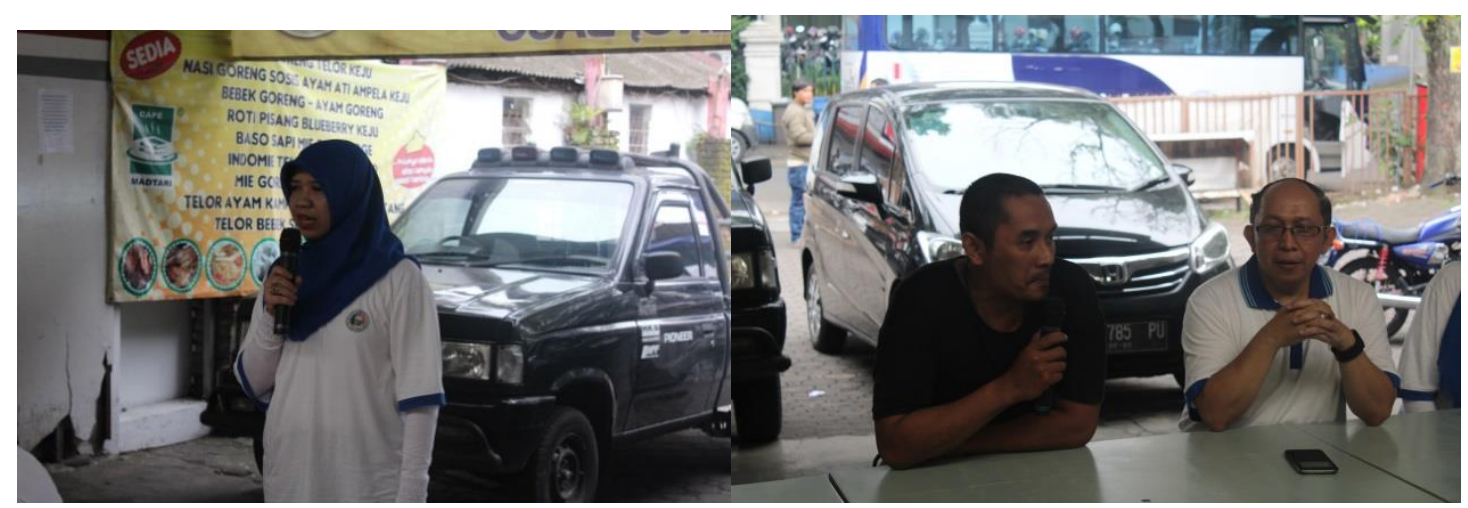

Gambar 2. Pembukaan dan Pelatihan PKM-P2UMKM

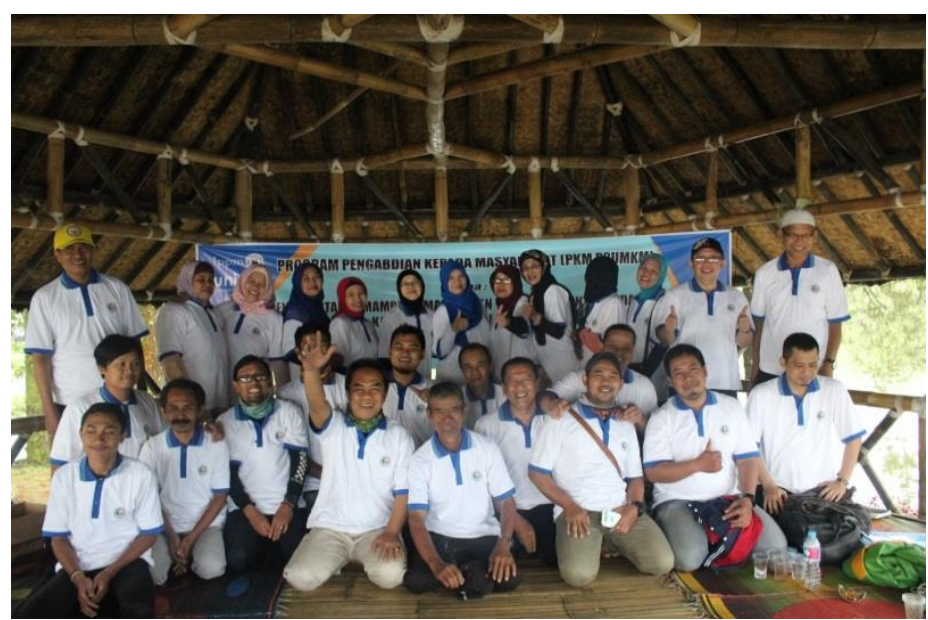

Gambar 3. Foto bersama setelah pelatihan

Evaluasi dilakukan dengan menyebarkan kuesioner kepada peserta pelatihan setelah pelaksanaan pelatihan selesai. Kuesioner berisi pertanyaan mengenai keterangan peserta pelatihan (jenis usaha yang dilakukan dan lama waktu menjadi pedagang kaki lima), tanggapan peserta pelatihan terhadap pelaksanaan pelatihan (materi pelatihan, fasilitas pelatihan, metode pelatihan, pemateri, pengaruh pelatihan yang dirasakan peserta), serta kritik dan saran untuk perbaikan kegiatan pelatihan.

3. Gambaran mengenai PKL

a. Jenis Usaha yang dijalankan oleh PKL didominasi oleh usaha makanan yaitu sekitar 74\%, Usaha minuman sekitar 10\%, sedangkan usaha selain makanan dan minuman sekitar $16 \%$.

b. Jika dilihat dari lama usaha sebagai PKL,sebagian besar PKL telah menjalankan usaha lebih dari 6 tahun yaitu sekitar $63 \%$.

2. Tanggapan peserta terhadap pelatihan yang telah dilakukan

a. Mengenai pemateri dari PKL yang telah sukses, sebagian besar (sekitar $68 \%$ ) peserta berpendapat bahwa mereka termotivasi untuk berhasil seperti pemateri.

b. Tanggapan peserta terhadap materi yang disampaikan pada saat pelatihan, sekitar 53\% peserta menilai materi yang diberikan sesuai dengan kebutuhan PKL. 
c. Untuk tanggapan terhadap buku saku yang diberikan, sekitar $47 \%$ peserta menilai buku saku yang dibagikan oleh tim pelaksana PKM dapat dibaca dan memiliki tampilan cukup baik.

d. Tanggapan terhadap fasilitas pelatihan (konsumsi dan transportasi, dan fasilitas lainnya), sebagian besar peserta menilai bahwa fasilitas yang diberikan pada saat pelatihan baik.

e. Tanggapan peserta terhadap metode Pelatihan yang diadakan di luar kelas, sebagian besar peserta menilai bahwa pelatihan diluar kelas menarik bagi mereka.

3. Kritik dan saran peserta terhadap pelatihan yang telah dilakukan

a. Sebagian besar peserta tidak menyampaikan kritik terhadap pelaksanaan pelatihan, akan tetapi $21 \%$ peserta meminta agar materi diperbaiki untuk pelaksanaan yang akan datang dan mengucapkan terimakasih atas dilaksanakannya pelatihan bagi PKL dilingkungan Unisba.

b. Untuk saran, $37 \%$ peserta menyarankan untuk melaksanakan kegiatan serupa di tahun mendatang dengan jumlah peserta yang ditambah dan lingkup materi yang diperluas. Sekitar $21 \%$ memberikan saran lain yang di luar konteks.

\section{Kesimpulan}

Secara umum kegiatan pengabdian kepada masyarakat program pembinaan usaha mikro kecil dan menengah (P2UMKM) berjalan sesuai dengan rencana awal. Dari pelaksanaan PKM yang dilakukan, dapat ditarik kesimpulan sebagai berikut :

1. Pedagang kaki lima di lingkungan Kampus Unisba Tamansari 1 berjumlah lebih dari 40 pedagang dengan berbagai jenis barang dagangan seperti makanan, minuman, dan pulsa. Sebagian besar pedagang tidak menggunakan manajemen usaha yang teratur dalam melakukan usaha. Cara yang digunakan hanya membeli bahan baku, memproduksi barang dagangan, dan menjual. Tidak ada mekanisme pencatatan mengenai kegiatan usaha yang dilakukan per hari.

2. Secara umum, peserta memberi nilai baik pada kegiatan PKM yang dilakukan. Mengenai pemateri dari PKL yang telah sukses, sebagian besar (sekitar 68\%) peserta berpendapat bahwa mereka termotivasi untuk berhasil seperti pemateri. Tanggapan peserta terhadap materi yang disampaikan pada saat pelatihan, sekitar 53\% peserta menilai materi yang diberikan sesuai dengan kebutuhan PKL.

3. Permasalahan yang masih terjadi dan dinilai para pedagang sebagai hambatan untuk berkembang adalah jumlah saingan (jumlah pedagang) yang semakin banyak dan jumlah modal usaha yang dibutuhkan semakin besar.

4. Kegiatan pembentukan paguyuban pedagang kaki lima di lingkungan Unisba belum dilakukan dengan baik dikarenakan bertepatan dengan masa pergantian Rektor di Unisba sehingga pelaksanaan inisiasi untuk pembentukan paguyuban pedagang kaki lima harus ditunda untuk memulai kembali koordinasi dengan Rektor Unisba yang baru.

Pelatihan manajemen kewirausahaan bagi pedagang kaki lima sebaiknya terus dilakukan bahkan diagendakan minimal satu tahun sekali untuk membekali pedagang kaki lima Unisba sehingga kegiatan usaha mereka terus berkembang dan memberi pelayanan yang lenih baik bagi seluruh pihak yang beraktivitas di lingkungan kampus Unisba Tamansari khususnya.. 


\section{Daftar Pustaka}

Genoveva, (2002), Mengenal Lebih Dekat: Kewirausahaan, Jurnal Ekonomi Perusahaan, Jakarta, STIE IIBI,.

Dzikron, M., (2013), Pengantar manajemen wirausaha, pedoman untuk mahasiswa dan calon pengusaha, draft buku ajar di PS TI Unisba.

Nugraha, Nasution A., dan Amaranti R., (2015), Modul Pelatihan Manajemen Wirausaha Untuk Mahasiswa dan Alumni, Universitas Islam Bandung

Rusriyanto, Dwi Joko, (2015), Kegiatan Pengabdian kepada Masyarakat (PkM) bagi Pedagang Kaki Lima (PKL) Binaan di Provinsi DKI Jakarta.

Rosita, Popy, (2006), Kajian Karakteristik Pedagang Kaki Lima (PKL) dalam Beraktifitas dan Memilih Lokasi Berdagang di Kawasan Perkantoran Kota Semarang.

Yohnson, (2003), Peranan Universitas Dalam Memotivasi Sarjana Menjadi Young Entepreneurs, Jurnal Manajemen dan Kewirausahaan, Universitas Kristen Petra, Surabaya, Vol 5 No.2 September 2003.

Jones, B.F., Rasmussen, C.M., dan Moffitt, M.C., (1997), Real Life problem solving: A collaborative approach to interdisciplinary learning. Washington, DC: American Psychological Association,.

GG Meredith, G. G., Nelson, R. E., dan Neck, P. A. (2002), The Practice of Entrepreneurship. Geneva: International Labour Organization. 